\title{
Rhein Derivative 4F Inhibits the Malignant Phenotype of Breast Cancer by Downregulating Rac1 Protein
}

OPEN ACCESS

Edited by:

Robert Clarke

Georgetown University, United States

Reviewed by:

César López-Camarillo,

Universidad Autónoma de la Ciudad

de México, Mexico

Laurence A. Marchat,

National Polytechnic Institute of

Mexico (IPN), Mexico

${ }^{*}$ Correspondence:

Yanhua Chen

chenyanhuah@163.com

Danrong Li

danrongli@163.com

${ }^{t}$ The authors have contributed equally to this work

Specialty section:

This article was submitted to Pharmacology of Anti-Cancer Drugs,

a section of the journal

Frontiers in Pharmacology

Received: 19 January 2020

Accepted: 06 May 2020

Published: 28 May 2020

Citation:

Li X, Liu Y, Zhao Y, Tian W, Zhai L, Pang $H$, Kang J, Hou H, Chen $Y$ and Li D (2020) Rhein Derivative

$4 F$ Inhibits the Malignant

Phenotype of Breast Cancer by Downregulating Rac1 Protein.

Front. Pharmacol. 11:754.

doi: 10.3389/fphar.2020.00754

\author{
Xinxiao $\mathrm{Li}^{1 \dagger}$, Yunfeng Liu ${ }^{1 \dagger}$, Yuhua Zhao ${ }^{1}$, Wei Tian ${ }^{2}$, Lina Zhai ${ }^{3}$, Huifeng Pang ${ }^{1}$, \\ Jiankang Kang ${ }^{3}$, Huaxin Hou ${ }^{2}$, Yanhua Chen ${ }^{1 *}$ and Danrong $\mathrm{Li}^{1,3^{*}}$ \\ ${ }^{1}$ Department of Basic Research, Guangxi Medical University Cancer Hospital, Nanning, China, ${ }^{2}$ College of Pharmacy, \\ Guangxi Medical University, Nanning, China, ${ }^{3}$ Life Sciences Institute, Guangxi Medical University, Nanning, China
}

Background: Triple-negative breast cancer is a common malignant tumor with unfavorable prognosis affecting women worldwide; thus, there is an urgent need for novel therapeutic drugs with improved anti-tumor activity. Rac family small GTPase 1 (Rac1) plays an important role in malignant behavior and is a promising therapeutic target. We reported an anthraquinone compound, Rhein, and its derivative, 4F, and investigated their downregulation effects on Rac1 in breast cancer cells in vitro.

Methods: The inhibition of cell proliferation by derivative 4F was investigated in two breast cancer (MDA-MB-231 and MCF-7) and normal breast (MCF-10A) cell lines by cell counting kit-8 assay and growth curves. The role of $4 \mathrm{~F}$ in cell migration and invasion and cytoskeletal change were assessed by Transwell chamber assay and F-actin staining, respectively. The affinity of Rhein and its derivative for Rac1 protein and the regulation of Rac1 promoter activity were evaluated by molecular docking software and luciferase reporter gene assay, respectively. Rac1 protein expression was determined by western blot assay.

Results: Compared to Rhein, derivative 4F more strongly inhibited breast cancer cell proliferation, migration, and invasion and also cause cytoskeletal changes like those in paclitaxel. Derivative 4F not only bound more stably to Rac1 but also inhibited Rac1 promoter activity in cells and downregulated Rac1 protein expression.

Conclusions: Rhein derivative 4F is a new anthraquinone compound with better antitumor activity than that of the lead compound Rhein in breast cancer. It down-regulated Rac1 expression and may be a small molecule inhibitor of Rac1.

Keywords: Rhein derivative, drug design, Rac family small GTPase 1, breast cancer, anticancer 


\section{INTRODUCTION}

Breast cancer is one of the most common malignant tumors in women worldwide. In the past decade, the overall breast cancer incidence rates among Asians/Pacific Islanders increased at an annual rate of 1.7 percent, faster than that of other ethnic groups (DeSantis et al., 2017). Triple-negative breast cancer is characterized by negativity for estrogen receptor (ER), progesterone receptor (PR), and human epidermal growth factor receptor (HER-2). Patients with triple-negative breast cancer typically have unfavorable prognosis owing to a lack of recognized molecular targets for therapy. Chemotherapy is the only established therapeutic option for triple-negative breast cancer, for which anthraquinone anti-tumor antibiotics are the cornerstone (Bianchini et al., 2016; Denkert et al., 2017). However, despite triple-negative breast cancer responses to chemotherapy in the early stage of treatment, drug resistance tends to develop rapidly due to cancer cell's heterogeneity (Cao et al., 2019). Hence, there is an urgent need for novel therapeutic drugs to more efficiently combat triple-negative breast cancer.

Rhein (1,8-dihydroxy-3-carboxy anthraquinone) (Figure 1A) is an anthraquinone compound extracted from plants such as rhubarb and polygonum multiflorum (Lu et al., 2016). Recent studies have shown that Rhein exhibited broad-spectrum anticancer activity by a variety of mechanisms in tongue cancer, stomach cancer, liver cancer, lung adenocarcinoma, granulocyte leukemia, and breast cancer (Shi et al., 2008; Chen et al., 2010; Fernand et al., 2011; Li et al., 2012; Zhou et al., 2015; $\mathrm{Wu}$ et al., 2017), suggesting the potential of Rhein as a lead compound in the design of anticancer drugs. However, Rhein is insoluble in water (Yajun and Zhen, 2009), which limits its bioavailability.

Rac family small GTPase 1 ( Rac1) is a member of the Rac subfamily of the GTPase Rho family (Payapilly and Malliri,
2018). It is encoded by RAC1 to produce a variety of alternatively spliced Racl proteins that play important roles in cell growth, cytoskeletal reorganization, protein kinase activation, cell cycle, cell adhesion, and cell movement (Bosco et al., 2009). A recent study published in Nature suggested that Rac1 may be a priority target for cancer therapy, with evidence to support its feasibility (Behan et al., 2019).

In a previous study, we screened different anthraquinone compounds and a series of tumor proteins with different docking software and scoring functions or algorithms by molecular docking computer-aided drug design and found that Rhein can stably bind Rac1 (Jing et al., 2015; Zhengying et al., 2017). Our previous tumor biological experiments also showed that Rhein plays an anti-tumor role by combining Rac1 (Tang et al., 2016; Zhou et al., 2017). To improve the anti-tumor activity of Rhein, based on previous studies, we modified the structure of Rhein and synthesized a series of derivatives, including derivative RP-4 which enhanced the radiosensitivity of nasopharyngeal carcinoma (Su et al., 2019) and derivative 4a, which inhibited ovarian cancer cell migration and invasion (Pang et al., 2020) and killed liver cancer cells by inducing para-apoptosis (Tian et al., 2019), etc. Among them, derivative $4 \mathrm{~F}$ showed superior anti-breast cancer effects and good bioavailability. The present study further investigated the inhibitory effect of derivative 4F on breast cancer cell proliferation, invasion, and metastasis in vitro and explored its mechanisms, especially the regulation of Rac1 protein expression.

\section{MATERIALS AND METHODS}

\section{Reagents}

The chemical formula of derivative $4 \mathrm{~F}$ is $\mathrm{C}_{35} \mathrm{H}_{33} \mathrm{~N}_{2} \mathrm{O}_{6}(1,8$-bis (benzyloxy)-3-(4-(2-hydroxyethyl) piperazine-1-carbonyl)-9,10-
A<smiles>O=C(O)c1cc(O)c2c(c1)C(=O)c1cccc(O)c1C2=O</smiles>

B<smiles>O=C1c2cccc(OCc3ccccc3)c2C(=O)c2c(OCc3ccccc3)cc(C(=O)N3CCN(CCO)CC3)cc21</smiles><smiles>CCN(CC)CCCC(C)Nc1nc(C)cc(Nc2ccc3nc(C)cc(N)c3c2)n1</smiles>

FIGURE 1 | The structure of the ligand molecules drawn in Chem Office Ultra 12.0 software. Both Rhein acid and derivative 4F contain an anthraquinone ring, while derivative 4F and NSC23766 contain nitrogen heterocyclic rings in common. Molecular structure of (A) Rhein, (B) derivative 4F, and (C) NSC23766. 
anthraquinone) (Figure 1B), with a relative molecular mass of 577 and $>98 \%$ purity [high-performance liquid chromatography (HPLC)]. Derivative 4F is a yellow flaky crystal that is slightly soluble in water and soluble in organic solvents such as dimethyl sulfoxide (DMSO), with a melting point of $155-157^{\circ} \mathrm{C}$. Rhein was purchased from Langze (Nanjing, China), vincristine (VCR) was purchased from Wanle (Shenzhen, China), paclitaxel (PTX) was purchased from Yangzijiang (Jiangsu, China), cisplatin (DDP) was purchased from Haosen (Jiangsu, China), and Racl activator PMA and Racl inhibitor NSC23766 were purchased from Selleck (Houston, USA).

\section{Cell Culture}

The human triple-negative breast cancer MDA-MB-231 and ERsensitive breast cancer MCF-7 cell lines were obtained from the American Type Culture Collection (ATCC). The human normal breast MCF-10A cell line was obtained from the China Center for Type Culture Collection (CCTCC). Cells were cultured in Dulbecco's Modified Eagle's Medium (DMEM) containing 10\% fetal bovine serum and penicillin $(100 \mathrm{U} / \mathrm{ml})$ and streptomycin $(100 \mathrm{mg} / \mathrm{L})$ in a humidified incubator with a volume fraction of $5 \% \mathrm{CO}_{2}$ at $37^{\circ} \mathrm{C}$.

\section{Cell Proliferation Assay}

Breast cancer MDA-MB-231 cells, MCF-7 cells, and human normal breast MCF-10A cells were used to evaluate cell viability. The cells were incubated in a 96-well plate at a density of 5,000 cells/well for $24 \mathrm{~h}$ and then exposed to different concentrations of Rhein (10-320 $\mu \mathrm{mol} / \mathrm{L})$ or derivative $4 \mathrm{~F}(2.5-40 \mu \mathrm{mol} / \mathrm{L})$. Cells without any drug were used a control. After incubation, $100 \mu \mathrm{L}$ of $10 \%$ cell counting kit-8 (CCK-8) solution was added to each well by liquid exchange method and incubated for $1 \mathrm{~h}$. The absorbance value [optical density (OD)] of each well was measured at $450 \mathrm{~nm}$ on a Synergy H1 microplate reader (BioTek Instruments, Inc., USA). The half-maximal inhibitory concentration $\left(\mathrm{IC}_{50}\right)$ was calculated using IBM SPSS Statistics for Windows, version 20.0. after $48 \mathrm{~h}$ of treatment. We plotted the growth curves of MDA-MB-231 and MCF-7 cells and calculated the doubling times. Cells were added to each well of a 6 -well plate and incubated for $24 \mathrm{~h}$ before $4 \mu \mathrm{mol} / \mathrm{L}$ Rhein or derivative $4 \mathrm{~F}$ were added. One 6-well plate was taken every $24 \mathrm{~h}$ to collect cells from each well to count by cytometer (Beckman Culter Z 1, USA). The doubling time (DT) was calculated as follows:

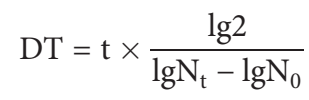

where the $t$ was the culture time, $N_{o}$ was the number of cells recorded for the first time ( $24 \mathrm{~h}$ after cell inoculation), and $N_{t}$ was the number of cells after time $t$.

\section{Cell Migration and Invasion Assay}

After withdrawing the fetal bovine serum, the cells were starved for $24 \mathrm{~h}$. A total of $4 \times 10^{4}$ cells $(200 \mu \mathrm{l})$ were added to the Transwell chamber and $600 \mu \mathrm{l}$ of a medium containing $20 \%$ fetal bovine serum was added to the lower chamber of the 24 -well plate. After adding $100 \mu \mathrm{l}$ of Rhein or derivative $4 \mathrm{~F}$ to the chamber, the final drug concentrations were $8 \mu \mathrm{mol} / \mathrm{L}$. The control was added with $100 \mu \mathrm{l}$ serum-free medium. The cells were incubated for $24 \mathrm{~h}$; next, the cells and liquid on the surface of the upper chamber membrane were wiped with a cotton swab, fixed with methanol, air-dried with phosphate-buffered saline (PBS), and stained with $0.2 \%$ crystal violet. Each chamber was photographed under a microscope at $20 \times$ magnification from five different fields of view: upper, lower, left, right, and middle. The migrated cells were finally counted using ImageJ. Cell invasion ability was measured similarly except that the bottom of the Transwell chamber membrane was coated with Matrigel before the cells were added.

\section{Cytoskeleton Staining Assay}

A total of $2 \times 10^{4}$ cells were incubated in each well of a 6-well plate with a built-in sterile cell slide for $24 \mathrm{~h}$ and then treated with drugs (Rhein $50 \mu \mathrm{mol} / \mathrm{L}$, derivative 4F $8 \mu \mathrm{mol} / \mathrm{L}$, VCR $200 \mathrm{nmol} / \mathrm{L}$, PTX $100 \mathrm{nmol} / \mathrm{L}, \mathrm{DDP} 10 \mu \mathrm{mol} / \mathrm{L}$ ) for $48 \mathrm{~h}$. The cell slides were washed with PBS, fixed with ice-cold acetone, and blocked with $0.2 \%$ TritonX-100 and $1 \%$ bovine serum albumin (BSA). The samples were placed in an icebox and F-actin reagent R37110 (Life Technologies, USA) and PBS were added and the samples were slowly shaken for 30-45 min. Next, the dye solution was removed and 4',6-diamidino-2-phenylindole (DAPI) was added to dye the nucleus. The samples were then washed with PBS, blocked with glycerin, and the cytoskeleton observed and photographed by laser confocal microscopy (Nikon A1, Japan) from 3 different fields of view. The assay was repeated for 3 times.

\section{Molecular Docking}

Molecular Operating Environment (MOE. 2008, CCG Montreal, Canada) (Vilar et al., 2008) was used to study the interaction between compound molecules and Racl protein as a receptor. The ASE scoring function in MOE was used to calculate the conformational strength of each compound bound to Rac1, with the lowest ASE score indicating the optimal conformation. The ligand molecules were Rhein, derivative $4 \mathrm{~F}$, and the positive control NSC23766 (Figure 1C).

\section{Luciferase Reporter Assay}

A lentivirus containing a RAC1-promoter-Luc2 plasmid was previously developed by our group and verified by double enzyme digestion assay (Li et al., 2019). Human RAC1 promoter (GenBank: NM_006908) was used as the target sequence to design and synthesize the pUC57-RAC1-promoter-Luc2 vector and recombined with the pLVX-AcGFP-Puro vector to construct the pLVX-RAC1-Luc2-GFP-Puro plasmid so that the RAC1 gene promoter was accurately inserted upstream of the luciferase gene. Lipofectamine ${ }^{\mathrm{TM}} 2000$ reagent was then used to transfect the recombinant and viral package plasmids into 293T cells for packaging. The lentiviral supernatant containing RAC1-promoterLuc2 plasmid was collected for future use. In this study, MDA-MB231 cells at a density of $5 \times 10^{4}$ cells/ml were seeded into 6-well plates and $500 \mu \mathrm{l}$ of virus solution was added $24 \mathrm{~h}$ later. After $48 \mathrm{~h}$ of continuous infection, the cells were seeded into a $T 25 \mathrm{~cm}^{2}$ culture flask at a dilution of 1:100 so that the cells were completely dispersed 
and cultured as single cells. After screening for 2 weeks with medium containing puromycin $(2 \mu \mathrm{g} / \mathrm{ml})$, a cell line stably expressing luciferase, MDA-MB-231-RAC1-Luc2, was obtained. The MDA-MB-231-RAC1-Luc2 cells were incubated in 96-well plates at $1 \times 10^{4}$ cells/well. After $24 \mathrm{~h}$ of adherence, the corresponding drug concentrations (PMA $10 \mu \mathrm{mol} / \mathrm{L}$, NSC23766 $25 \mu \mathrm{mol} / \mathrm{L}$, Rhein $50 \mu \mathrm{mol} / \mathrm{L}$, derivative $4 \mathrm{~F} 2,4$, and $8 \mu \mathrm{mol} / \mathrm{L}$ ) or serum-free medium were added. The effects of the compounds on luciferase assay in the MDA-MB-231-RAC1-Luc2 cell line were evaluated using the ONE-Glo ${ }^{\mathrm{TM}}$ Reagent (Promega, Madison, WI, USA).

\section{Western Blot Assay}

Cells were first treated with different drugs and then collected and lysed with radioimmunoprecipitation assay (RIPA) lysate. After centrifugation, the supernatant was taken. The total protein concentration was determined by bicinchoninic acid (BCA) method and protein samples were denatured at $100^{\circ} \mathrm{C}$ for 5 min. After electrophoresis with $10 \%$ sodium dodecyl sulfonatepolyacrylamide (SDS-PAGE) gel, the proteins were transferred to a $0.22 \mu \mathrm{m}$ nitrocellulose (NC) membrane. The membrane was blocked with 5\% skim milk powder at room temperature for $2 \mathrm{~h}$ and incubated with the primary antibodies against glyceraldehyde 3-phosphate dehydrogenase (GAPDH, 1:1000) and Racl (1:500) at $4^{\circ} \mathrm{C}$ overnight. After rinsing with trisbuffered saline, $0.1 \%$ Tween 20 (TBST), fluorescence secondary antibody $(1: 500,1: 10,000)$ was added and incubated at room temperature for $1.5 \mathrm{~h}$. The proteins bands were quantified using an Odyssey Imaging System (LI-COR, USA).

\section{Statistics}

The experimental results and data were analyzed in SPSS. The measurement data were presented as means \pm standard deviation (mean $\pm \mathrm{SD}$ ) and the experiment was repeated three times independently. One-way analysis of variance (ANOVA) was used to compare multiple groups. Least significant difference (LSD) $t$-tests were used for comparisons between groups. $P<0.05$ was considered statistically significant.

\section{RESULTS}

\section{Derivative 4F Inhibits Breast Cancer Cell Proliferation}

Under the same concentrations $2.5-40 \mu \mathrm{mol} / \mathrm{L}$ of derivative $4 \mathrm{~F}$ treatment, comparison of derivative $4 \mathrm{~F}$ on the cytotoxicity of breast cancer MDA-MB-231, MCF-7, and normal breast MCF$10 \mathrm{~A}$ cells, showed significantly lower cytotoxicity of derivative $4 \mathrm{~F}$ to normal breast cells than that to breast cancer cells (Figure 2A). Moreover, its toxicity to human triple-negative breast cancer MDA-MB-231 cells in this concentration range was time- and dose-dependent (Figure 2B). The $\mathrm{IC}_{50}$ values of derivative $4 \mathrm{~F}$ and Rhein were $(12.80 \pm 0.83)$ and (163.96 \pm 33.36$)$ $\mu \mathrm{mol} / \mathrm{L}$ in MDA-MB-231 cells and $(7.54 \pm 1.25) \mu \mathrm{mol} / \mathrm{L}$ and $(120.19 \pm 10.98) \mu \mathrm{mol} / \mathrm{L}$ in MCF-7 cells (Figur2C, G, H) (Yunfeng et al., 2019a; Yunfeng et al., 2019b). The IC $_{50}$ of derivative $4 \mathrm{~F}$ was much lower than that of the lead compound
Rhein. The growth curves of MDA-MB-231 and MCF-7 cells are shown in Figures 2D, E. In both cell lines, after treated with $4 \mu \mathrm{mol} /$ L Rhein or derivative $4 \mathrm{~F}$, cell growth under derivative $4 \mathrm{~F}$ treatment was much slower than those in the Rhein and control groups. After derivative $4 \mathrm{~F}$ treatment, the doubling times of MDA-MB-231 and MCF-7 cells were 119.72 and $79.4 \mathrm{~h}$ respectively, much longer than the 26.6 and $31.8 \mathrm{~h}$ in the control group and 24.5 and $33.5 \mathrm{~h}$ in the Rhein group (Figure 2F).

\section{Derivative 4F Inhibits Breast Cancer Cell Migration and Invasion}

The migration and invasion ability of the human triple-negative breast cancer MDA-MB-231 cells was significantly higher than that of MCF-7 cells. The western blot revealed higher Rac1 expression in MDA-MB-231 cells than that in MCF-7 cells (Figure 3A). Therefore, the MDA-MB-231 cells were used to verify the effect of derivative $4 \mathrm{~F}$ on cell migration and invasion. The Transwell assay results showed migration cell numbers in the control, Rhein, and derivative $4 \mathrm{~F}$ groups of $(234 \pm 54),(189 \pm 37)$, and $(135 \pm 26)$, respectively. The numbers of invasive cells were ( $85 \pm 9),(65 \pm 10)$, and $(24 \pm 6)$, respectively (Figures $3 \mathbf{B}, \mathbf{C})$. The numbers in the derivative $4 \mathrm{~F}$ group were the lowest in both experiments.

\section{Derivative 4F Affects the Cytoskeleton in Breast Cancer Cells}

F-actin staining was used to observe the effects of Rhein and derivative $4 \mathrm{~F}$ on cellular cytoskeletons, using VCR, PTX, and DDP as positive controls. The main effects of derivative $4 \mathrm{~F}$ and other drugs on breast cancer MDA-MB-231 and MCF-7 cells were as follows (Figures 4A, B): the cells became round and wrinkled, the pseudopodia on the cell membrane disappeared, the intracellular microfilaments were significantly reduced and broken and concentrated around the nucleus, and some elongated microfilaments were disorganized and gathered in the nuclear membrane. Both of them showed similar reactions to those of PTX treatment (Figures 4C, D), which induces cell microfilament polymerization and inhibits microfilament depolymerization.

\section{Molecular Docking of Rac1 Protein and Derivative 4F}

Three compounds docked with Racl respectively. The docking results indicated that the compounds were bound to Racl with different conformations. According to the MOE. 2008 docking result, the binding stability of these three compounds to Rac1 is ranked from high to low: derivative 4F> NSC23766> Rhein (Table 1), and the optimal binding mode of these compounds with Rac1 protein calculated by ASE scoring function are shown in Figure 5.

The ASE scoring function value indicates the stability of the complex, such that a lower score represents a more stable complex. The ASE score mainly depends on the number and distance of hydrogen bonds; however, the number of aromatic cations and interacting amino acid residues also contribute to the complex stability. The binding energies of Rhein, derivative $4 \mathrm{~F}$, and NSC23766 docked with Rac1 protein were all less than -7.5 $\mathrm{kcal} / \mathrm{mol}$, indicating effective docking (Nicola et al., 2009). Rhein, 
A

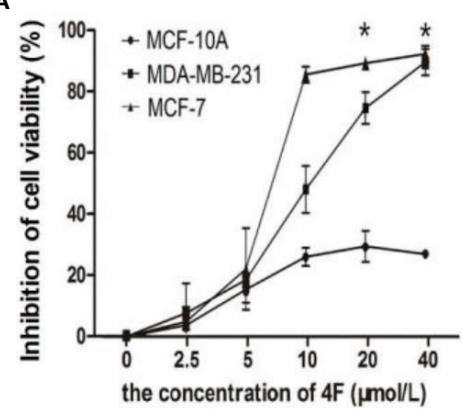

B

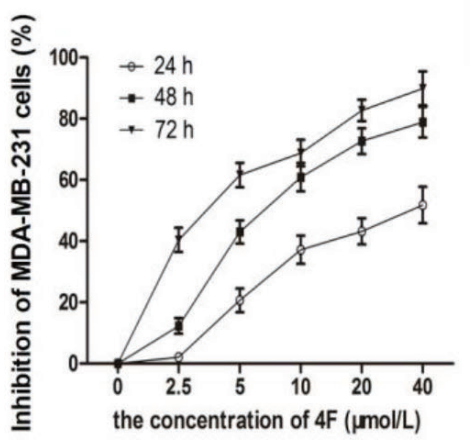

C

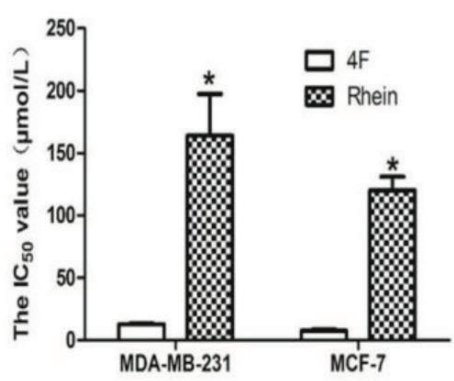

G

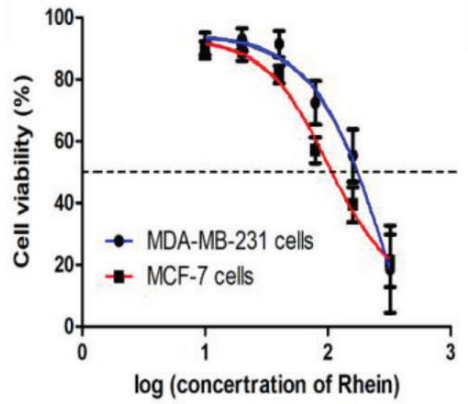

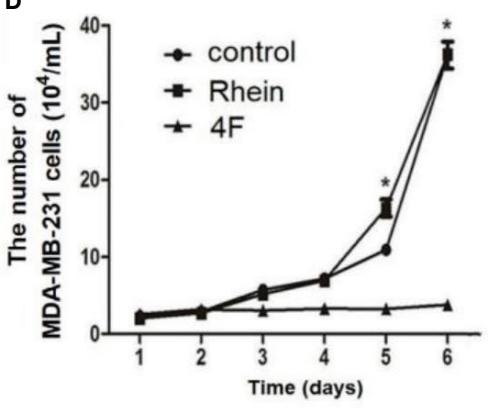

E
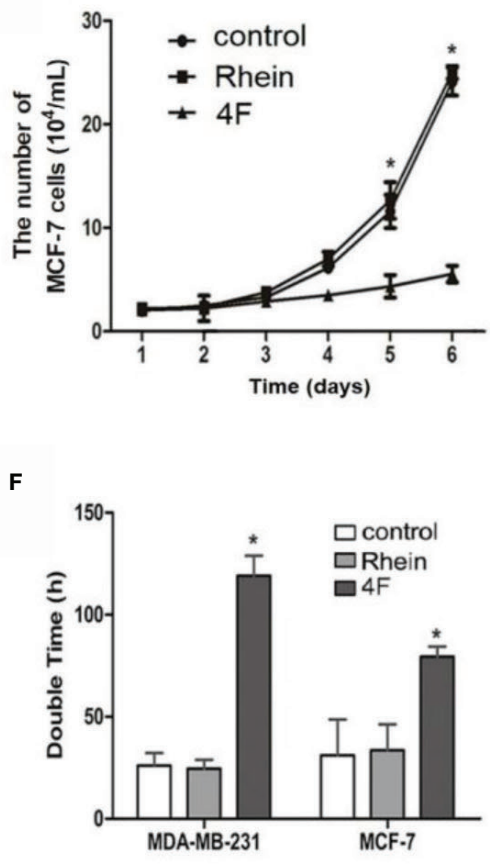

H

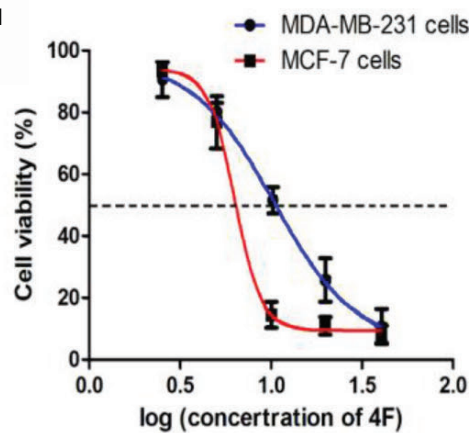

FIGURE 2 | Derivative 4F inhibition of breast cancer or normal cell proliferation. Control group corresponds to cells growing without any drug. Cell numbers were measured by cytometer. $I C_{50}$ values were calculated after $48 \mathrm{~h}$ of treatment. Data are shown as means $\pm S D(n=3)$, one-way analysis of variance (ANOVA) was used for statistical analysis. (A) Comparison of derivative $4 \mathrm{~F}$ cytotoxicity to breast cancer and normal breast cells. ${ }^{*} P<0.05$, comparison of MCF-10A group and MDA-MB-231 or MCF-7 group. (B) MDA-MB-231 cells treated with different concentrations of derivative $4 \mathrm{~F}$ for 24,48 , and $72 \mathrm{~h}$. (C) IC $\mathrm{C}_{50}$ values of the two breast cancer cell lines. ${ }^{*} P<0.05$, comparison of derivative $4 \mathrm{~F}$ group and Rhein group. (D) Growth curve of MDA-MB-231 cells. ${ }^{*} P<0.05$, comparison of derivative $4 \mathrm{~F}$ group and control group. (E) Growth curve of MCF-7 cells. ${ }^{*} P<0.05$, comparison of derivative $4 \mathrm{~F}$ group and control group. (F) Doubling time of two breast cancer cell lines. ${ }^{*} P<0.05$, comparison of derivative $4 \mathrm{~F}$ group and control group. (G) $I \mathrm{C}_{50}$ curve of Rhein in MDA-MB-231 and MCF-7 cells. (H) IC $\mathrm{C}_{50}$ Curve of derivative $4 \mathrm{~F}$ in MDA-MB-231 and MCF-7 cells. 

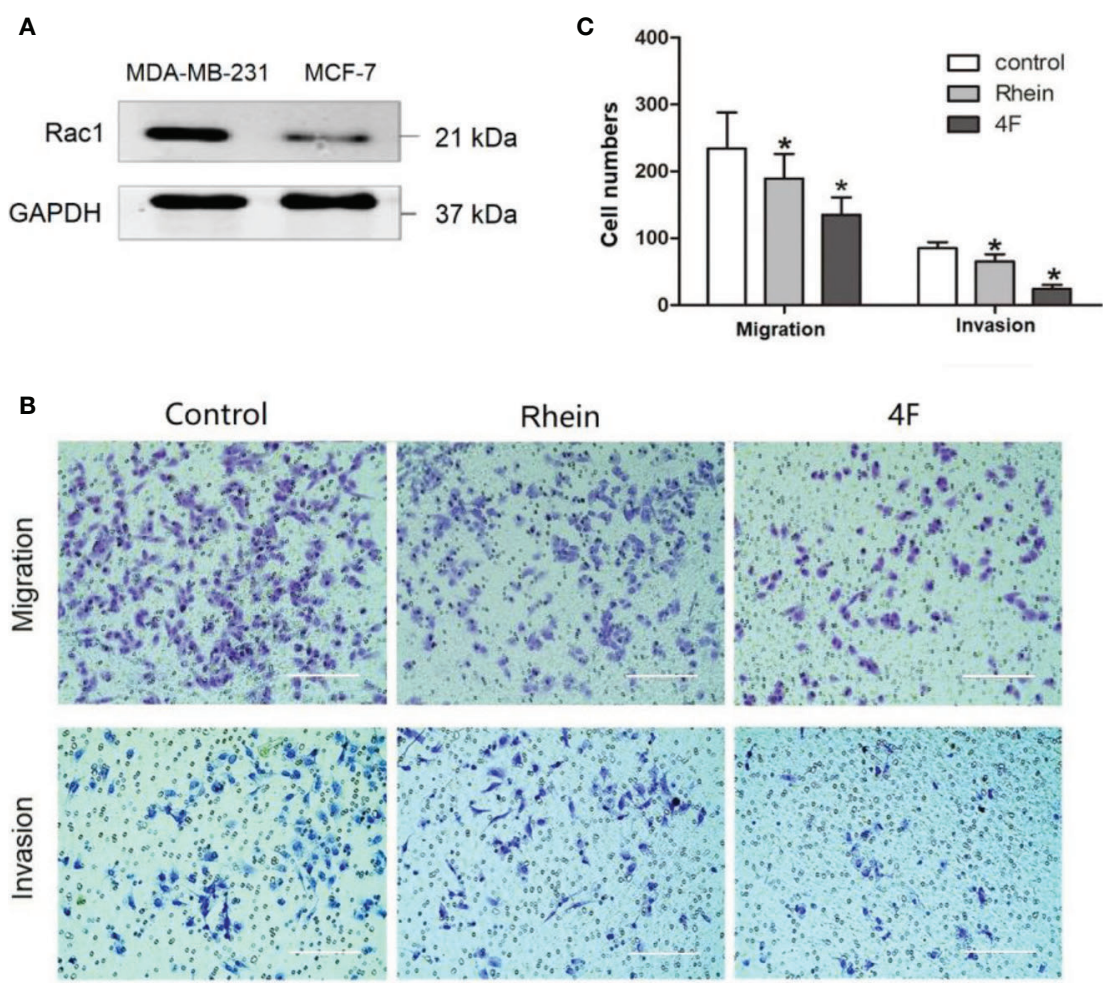

FIGURE 3 | Transwell assay to test MDA-MB-231 cell migration and invasion ability. The control group correspond to cells growing without any drug. (A) Rac1 protein expression in MDA-MB-231 and MCF-7 cells. (B) Transwell assay of MDA-MB-231 cells (scale bar: $200 \mu \mathrm{m})$. (C) Numbers migrated and invaded MDA-MB231 cells. Data are shown as means $\pm \mathrm{SD}(\mathrm{n}=5)$. One-way analysis of variance (ANOVA) was used for statistical analysis. ${ }^{*} P<0.05$, comparison of Rhein group or derivative 4F group and control group on MDA-MB-231 cells.

derivative 4F, and NSC23766 formed three, five, and two hydrogen bonds with Rac1, respectively, indicating the strongest interaction force for derivative $4 \mathrm{~F}$. In addition, compared to Rhein and NSC23766, derivative 4F formed the most aromatic cations and amino acid residues with Rac1, which contributed to the stronger hydrophobic and van der Waals force interactions.

\section{Derivative 4F Inhibits Rac1 Promoter Activity}

Luciferase activity reflects the transcriptional activity of the promoter; thus, detecting luciferase expression provides a rapid and cheap method for monitoring promoter activity (Wet et al., 1987). To validate the derivative $4 \mathrm{~F}$ regulation of Rac1, we constructed an MDA-MB-231-RAC1-Luc2 stable cell line containing the Racl promoter in the luciferase reporter vector. After puromycin screening, the transfection efficiency reached 90\% (Figure 6A), which means the MDA-MB-231-RAC1-Luc2 cells can be used to detect the regulatory effect of different compounds on Racl promoter activity. As shown in Figure 6B, after the cells were treated with different compounds, Racl activator PMA up-regulated the luciferase activity of Rac1, while NSC23766, Rhein, and derivative 4F inhibited Racl luciferase activity in cells. The luciferase activities of cells treated with derivative $4 \mathrm{~F}$ at 4 and $8 \mu \mathrm{mol} / \mathrm{L}$ were significantly reduced, comparable to the decrease observed for NSC23766 but at lower concentrations.

\section{Derivative 4F Downregulates the Expression of Rac1 Protein}

We used western blot assay to detect Racl protein expression in MDA-MB-231 and MCF-7 cells. We found that both Rhein and derivative $4 \mathrm{~F}$ down-regulated expression in both cell lines, but derivative $4 \mathrm{~F}$ worked at a lower concentration than did Rhein and had a more obvious effect on human triple-negative breast cancer MDA-MB-231 cells with high Rac1 expression. $2 \mu \mathrm{mol} / \mathrm{L}$ derivative $4 \mathrm{~F}$ could significantly affect MDA-MB-231 cells, while the corresponding concentration was $8 \mu \mathrm{mol} / \mathrm{L}$ on MCF-7 cells. Moreover, with the increase of derivative $4 \mathrm{~F}$ concentration, the expression of Rac1 protein decreased in a concentrationdependent manner in both cells (Figure 7).

\section{DISCUSSION}

According to the 2019 CSCO Breast Cancer Treatment and Treatment Guide, chemotherapy is an imperative treatment for triple-negative breast cancer due to the lack of special therapeutic 

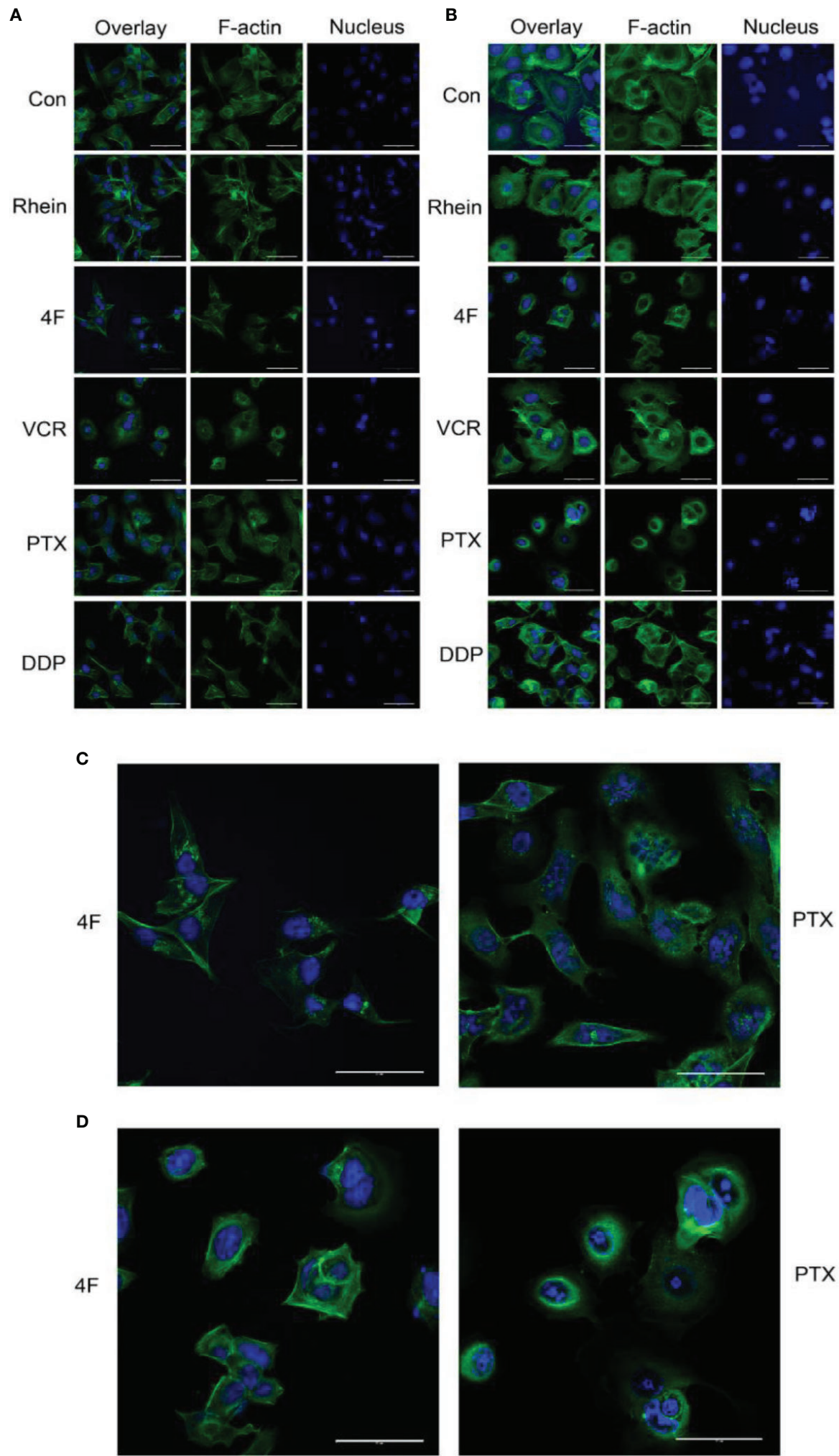

FIGURE 4 | Laser confocal microscopy to detect the effects of different drugs on the cytoskeleton of breast cancer cells (scale bar: 50 um). F-actin and the nucleus appear in green and blue, respectively. (A) Cytoskeletal changes after drug treatments in MDA-MB-231 cells. (B) Cytoskeletal changes after drug treatments in MCF7 cells. (C) MDA-MB-231 cells treated with derivative 4F and PTX (scale bar: $50 \mu \mathrm{m}$ ). (D) MCF-7 cells treated with derivative 4F and PTX (scale bar: $50 \mu$ m). 
TABLE 1 | ASE function score and molecular force of compounds docked with Rac1.

\begin{tabular}{|c|c|c|c|c|c|c|}
\hline \multirow{2}{*}{$\begin{array}{l}\text { Compounds } \\
\text { Rhein }\end{array}$} & \multirow{2}{*}{$\begin{array}{c}\text { The lowest Binding } \\
\text { energy (Kcal) }\end{array}$} & \multirow{2}{*}{$\begin{array}{l}\text { Hydrogen bond } \\
\text { Asn } 72\end{array}$} & \multirow{2}{*}{$\begin{array}{c}\begin{array}{c}\text { Distance of } \\
\text { hydrogen bond }(\AA)\end{array} \\
2.79\end{array}$} & \multirow[t]{2}{*}{$\begin{array}{l}\text { Arene-cation } \\
\text { interactions }\end{array}$} & \multicolumn{2}{|c|}{$\begin{array}{l}\text { Hydrophobic } \\
\text { interactions }\end{array}$} \\
\hline & & & & & Phe 141 & Ile 117 \\
\hline & & Gln 160 & 2.82 & & Leu 127 & \\
\hline & & Gln 101 & 2.85 & & Ala 97 & Leu 100 \\
\hline \multirow[t]{5}{*}{ Derivative 4F } & -22.9834 & Asn 129 & 2.76 & Arg 98 & Pro 67 & Ile 117 \\
\hline & & Asn 72 & 2.66 & Arg 98 & Leu 143 & Ile 113 \\
\hline & & Asn 72 & 2.76 & Phe 141 & Val 63 & Phe 141 \\
\hline & & Gln 101 & 2.57 & & Val 110 & Ala 97 \\
\hline & & Asn 129 & 3.10 & & Leu 127 & Leu 100 \\
\hline \multirow[t]{4}{*}{ NSC23766 } & -16.7129 & Arg 98 & 2.99 & Arg 114 & Val 110 & Ala 97 \\
\hline & & Asn 96 & 2.05 & Arg 114 & Ile 117 & Ile 113 \\
\hline & & & & & Phe 141 & Leu 100 \\
\hline & & & & & Leu 127 & \\
\hline
\end{tabular}

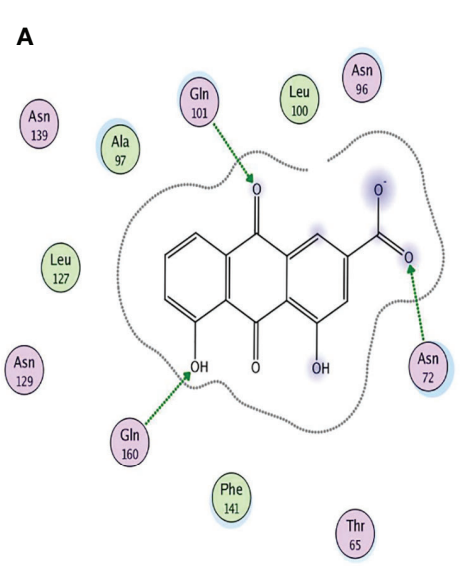

c

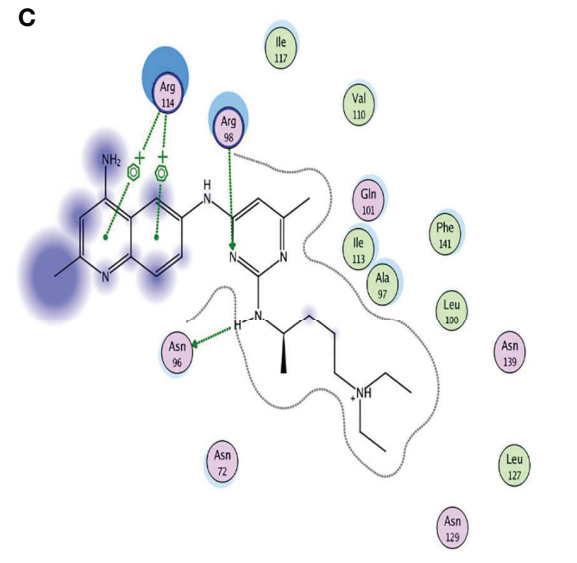

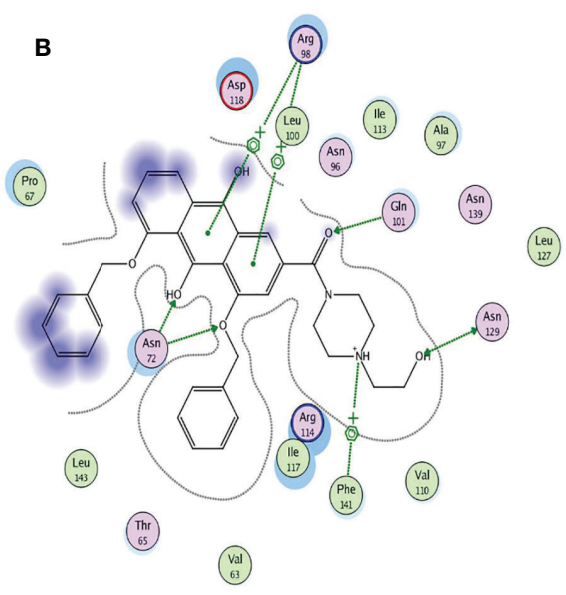

polar $\rightarrow$ sidechain acceptor $\bigcirc$ solvent residue $\quad 0$ Oarene-arene basic $\rightarrow$ backbone accepto greasy backbone donor $\begin{array}{ll}\text { proximity } & \text { ligand } \\ \text { contour } & \text { exposure }\end{array}$

metal complex 0 +arene-catio solvent contact metal contact $\mathrm{O}_{\text {exposure }}^{\text {receptor }}$

FIGURE 5 | Two-dimensional view of the interaction modes of minimum energy conformations of compounds with Rac1. Hydrogen bonds are shown as dotted arrows, greasy amino acid residues are shown as green circles, and polar amino acid residues are shown as pink circles. (A) Rac1-Rhein complex. (B) Rac1derivative 4F complex. (C) Rac1-NSC23766 complex.

targets. Anthraquinones, taxanes, and platinum-based drugs are commonly used for the treatment of breast cancer. Rhein is a natural anthraquinone compound with low toxicity that is well tolerated by humans. To produce additional anthraquinone compounds, researchers have focused on the structural modification of the 1,8-phenolic hydroxyl groups and 3carboxy of Rhein as a lead compound (Yao et al., 2014; Jiang et al., 2019). We produced the novel Rhein derivative $4 \mathrm{~F}$ by introducing a benzyloxy group to the 1,8-phenolic hydroxyl group, which induced endoplasmic reticulum stress, as well as 

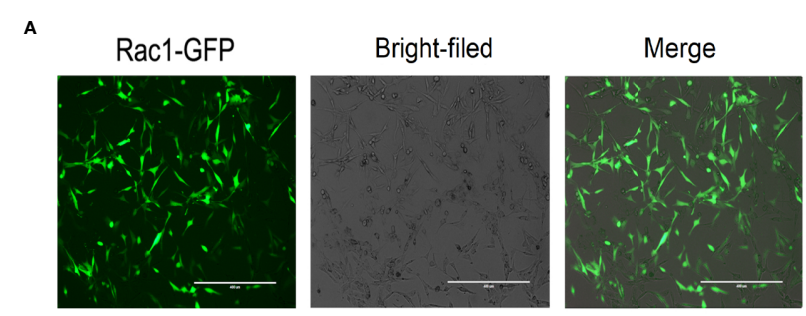

B

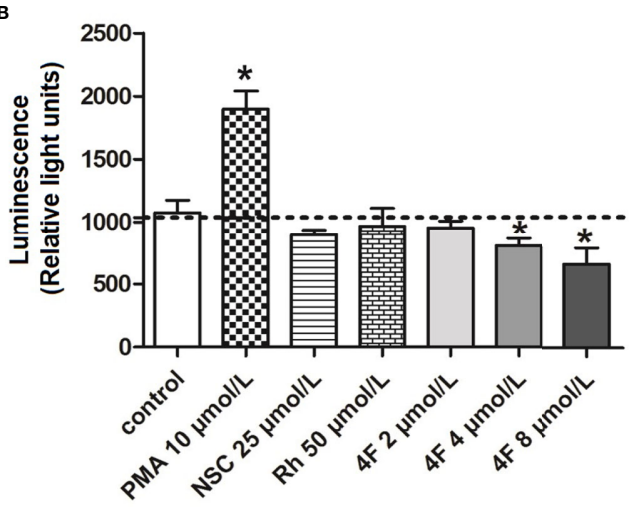

FIGURE 6 | Luciferase activity of Rac1 promoter in MDA-MB-231 cells treated with different compounds. (A) GFP-labeled MDA-MB-231 cells following Rac1promoter-Luc2 lentivirus transfection (scale bar: $400 \mu \mathrm{m}$ ). Under an inverted fluorescence microscope, almost all cells show green fluorescence with moderate intensity with a fluorescent cell count indicating a 90\% transfection efficiency. (B) Luciferase activity of Rac1. Data are shown as means \pm SD ( $n=$ 3). One-way analysis of variance (ANOVA) was used for statistical analysis. ${ }^{\star} P<0.05$, comparison of each compound group and control group.

a hydroxyethyl piperazine group to the 3-carboxyl group. Among nitrogen heterocycles, the piperazine motif has attracted considerable attention as its double nitrogen atom and hydrogen in water can form a hydrogen bond effect; thus, it has good hydrophilicity and can significantly increase the water solubility of the drug, while also improving the biological activity and enhancing the action of the drug (Patel and Se Won, 2013; Rathi et al., 2016). We found that derivative 4F inhibited cell growth in a time- and dose-dependent manner and also prevented excessive toxicity in normal breast cells when killing breast cancer cells. Furthermore, its inhibition on the proliferation and growth of breast cancer cells was also much stronger than that of Rhein and control, and greatly prolonging the doubling time of cancer cells. Our previous study also proved that derivative $4 \mathrm{~F}$ is far less cytotoxic to normal breast cells than doxorubicin (Yunfeng et al., 2019b). This indicates that the side chain of Rhein was successfully modified and that derivative $4 \mathrm{~F}$ is may be a selective anthracycline candidate with low toxicity. Based on this, we focused on the effect of derivative $4 \mathrm{~F}$ on the cancer cells in subsequent experiments.

Racl is a small $(21 \mathrm{kDa})$ signal GTPase. Numerous studies have suggested that Racl may be a therapeutic target for tumors ( $\mathrm{Ma}$ et al., 2009; McAllister, 2012; Stallings-Mann et al., 2012). Like other members of the Rho subfamily, Racl regulates a variety of signaling pathways that control corresponding physiological processes. We used the molecular docking computer-assisted drug design MOE software to evaluate the binding stability of derivative $4 \mathrm{~F}$ and Racl. The results showed that derivative $4 \mathrm{~F}$ formed more hydrogen bonds with Rac1; thus, the interaction force was stronger. In addition, derivative $4 \mathrm{~F}$ also formed more arenecation with Rac1 and formed hydrophobic interactions with more amino acid residues than those for Rhein and the positive control Rac1 inhibitor NSC23766. Therefore, the energy of the Rac1derivative $4 \mathrm{~F}$ complex was lower and derivative $4 \mathrm{~F}$ was more stable in combination with Racl. However, the evaluation of molecular docking software on the effect of compounds and Rac1 protein is only a theoretical speculation, and how the derivative $4 \mathrm{~F}$ fits in the binding pocket needs to be further confirmed. To rise from theory to practice, we also performed a luciferase reporter gene assay to explore whether derivative $4 \mathrm{~F}$ had a real regulatory effect on Racl in cells. In biological research, luciferase is often used as a reporter gene to evaluate the transcriptional activity of cells transfected with the luciferase gene under the control of the promoters of interest. Our results showed that derivative $4 \mathrm{~F}$ reduced the luciferase activity of Racl in a dose-dependent manner, which means derivative $4 \mathrm{~F}$ can practically inhibit Rac1 promoter activity in breast cancer cells. Meanwhile, the expression of Rac1 protein was also down-regulated by derivative $4 \mathrm{~F}$ in a dosedependent manner, which can prove the effective regulation of derivative $4 \mathrm{~F}$ on $\mathrm{Racl}$ to some extent.

Tumor recurrence and metastasis are inseparable from the microscopic infiltration and invasion ability of cells. Cancer cell growth and invasion of local and distant tissues require dysregulation of cell movement, which is an important sign of cancer cell invasion and metastasis. Our study showed higher Rac1 expression in triple-negative breast cancer MDA-MB-231 cells than that in MCF-7 cells, which may explain why MDAMB-231 cells showed stronger migration and invasion abilities. We also found that both Rhein and derivative 4F inhibited MDA-MB-231 cell migration and invasion, with significantly stronger inhibition by derivative $4 \mathrm{~F}$. Thus, derivative $4 \mathrm{~F}$, which is structurally modified, was superior to Rhein in inhibiting breast cancer cell migration and invasion. What counts is, this is probably done by affecting Racl because the western blot assay showed that derivative $4 \mathrm{~F}$ could down-regulate Racl protein expression in breast cancer cells at a lower effective concentration than that for Rhein. Furthermore, compared to MCF-7 cells, derivative $4 \mathrm{~F}$ showed a more obvious effect on human triplenegative breast cancer MDA-MB-231 cells with high Rac1 expression. These findings indicate that Racl may be an action site of derivative $4 \mathrm{~F}$ and Rhein and confirm the regulation of Rac1 expression by derivative $4 \mathrm{~F}$.

Tumor metastasis requires cytoskeletal remodeling. The cytoskeleton consists of microtubules, microfilaments (actin filaments), and intermediate filaments. It is a complex fibrous network structure. Some classical signaling pathways between microfilaments and their interacting proteins, such as the Rho GTP kinase signaling pathway, are important for tumor metastasis. The Rac family (Rac1, Rac2 and/or Rac3 depending on cell type and condition) can promote the formation of 


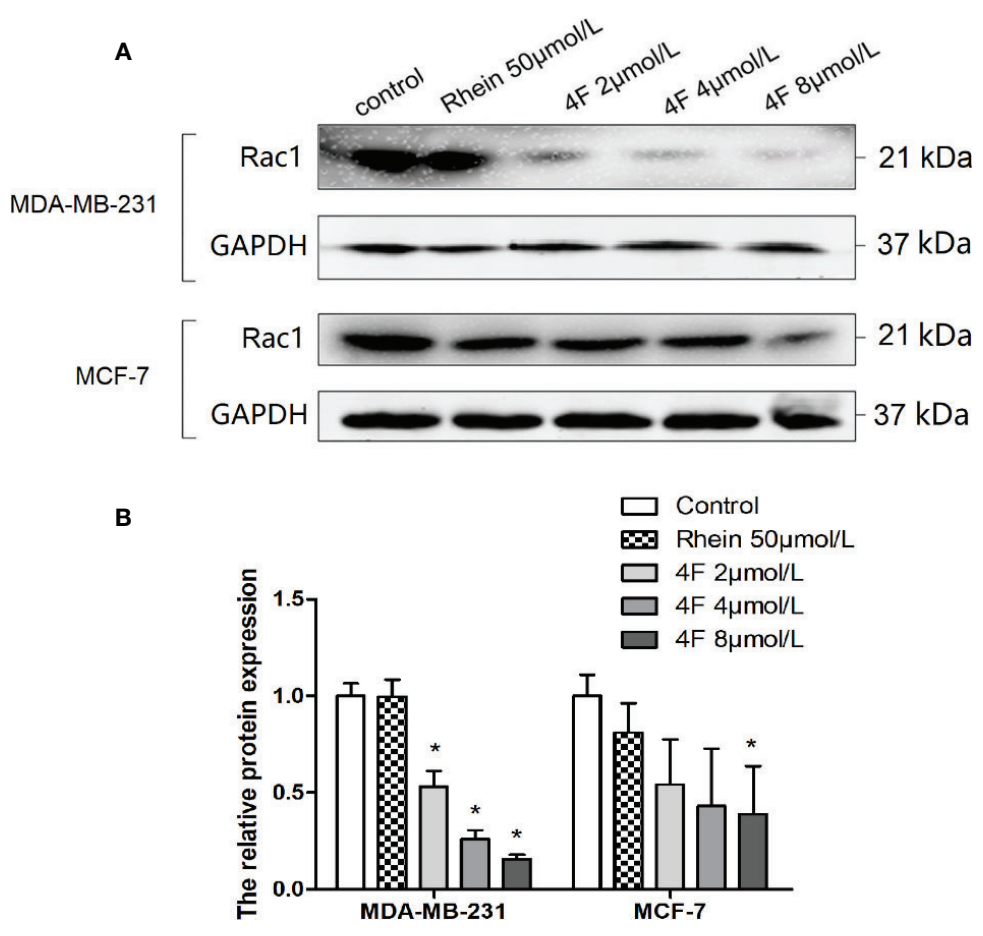

FIGURE 7 | Rac1 protein expression inhibition by Rhein and derivative 4F in breast cancer cells. (A) Western blot assay to detect Rac1 protein expression levels in MDA-MB-231 and MCF-7 cells. (B) The relative Rac1 protein expressions in MDA-MB-231 and MCF-7 cells. Rac1 expression (normalized against GAPDH) in the control groups was considered to be $100 \%$ in these two cell lines. Data are shown as means \pm SD $(n=3)$. One-way analysis of variance (ANOVA) was used for statistical analysis. ${ }^{*} P<0.05$, comparison of each treated group and control group.

numerous membrane extensions in lamellipodia by mediating actin polymerization and the lamellipodia have been shown to drive movement in many cells in vivo (Ridley, 2015). Similarly, Rac1 and other Rho proteins can control actin to affect cytoskeleton and microtubule dynamics through direct interactions with multiple effector proteins (Bosco et al., 2009). In this study, we chose three drugs as positive controls: the antimitotic drug VCR, which inhibits tubulin polymerization, and affects spindle microtubule formation; PTX, which induces microfilament polymerization and inhibits cell mitosis; and the cytotoxic drug DDP, which affects cellular DNA. Laser confocal microscopy showed that the effect of derivative $4 \mathrm{~F}$ on the cytoskeleton was similar to that of PTX, which can induce microfilament polymerization and inhibit microfilament depolymerization. Microtubules and microfilaments are interdependent and highly motile and participate in eukaryotic cell movement (Rosenblum and Shivers, 2000). PTX has been shown to have specific binding sites on microtubules, which can specifically and reversibly bind microtubules and inhibit motility (Parness and Horwitz, 1981; Yang and Horwitz, 2017). These findings suggest that derivative $4 \mathrm{~F}$ may restrain cell movement by controlling microtubule and microfilament activity, comparable to the action of PTX.

In summary, derivative $4 \mathrm{~F}$, a novel Rhein derivative with good cell selectivity, showed stronger lethality to breast cancer cells while being less toxic to normal breast cells. It not only showed a strong ability to bind Racl but also reduced the transcriptional activity of the Rac1 promoter, downregulated Racl protein expression in cells and caused microfilament rearrangement to inhibit cell invasion and metastasis. These findings suggest that derivative $4 \mathrm{~F}$ may be a small molecular inhibitor of Rac1 in breast cancer cells. The results of our study provide theoretical support for the structural modification and application development of Rhein and offer new ideas for the design of anti-tumor drugs and the development of therapeutic drugs for triple-negative breast cancer. However, the detailed molecular mechanism and signaling pathway by which derivative $4 \mathrm{~F}$ regulated Racl and its antitumor effects in vivo require further study.

\section{DATA AVAILABILITY STATEMENT}

The data supporting the conclusions of this article are available on request to the corresponding authors.

\section{ETHICS STATEMENT}

The study was approved by the Ethics Committee of Guangxi Medical University. 


\section{AUTHOR CONTRIBUTIONS}

YL performed and analyzed all the experiments. $\mathrm{HH}$ and WT drafted the work for important intellectual content. XL and DL edited the language and figures. YZ, LZ, HP, and JK collected and analyzed the data. $\mathrm{YC}$ and $\mathrm{HH}$ provided reagents and advice. All authors contributed to manuscript revision, read and approved the submitted version.

\section{FUNDING}

This work was supported by the National Natural Science Foundation of China (Grant No. 81460561 and 81360502), Guangxi Natural Science Foundation (Grant No. 2018GXNSFAA281064), Innovation Project of Guangxi Graduate Education (Grant No.YCSW2019107), and the Program of Key

\section{REFERENCES}

Behan, F. M., Iorio, F., Picco, G., Goncalves, E., Beaver, C. M., Migliardi, G., et al. (2019). Prioritization of cancer therapeutic targets using CRISPR-Cas9 screens. Nature 568 (7753), 511-516. doi: 10.1038/s41586-019-1103-9

Bianchini, G., Balko, J. M., Mayer, I. A., Sanders, M. E., and Gianni, L. (2016). Triple-negative breast cancer: challenges and opportunities of a heterogeneous disease. Nat. Rev. Clin. Oncol. 13 (11), 674-690. doi: 10.1038/nrclinonc.2016.66

Bosco, E. E., Mulloy, J. C., and Zheng, Y. (2009). Racl GTPase: a "Rac" of all trades. Cell Mol. Life Sci. 66 (3), 370-374. doi: 10.1007/s00018-008-8552-x

Cao, W., Li, J., Hao, Q., Vadgama, J. V., and Wu, Y. (2019). AMP-activated protein kinase: a potential therapeutic target for triple-negative breast cancer. Breast Cancer Res. 21 (1), 29. doi: 10.1186/s13058-019-1107-2

Chen, Y. Y., Chiang, S. Y., Lin, J. G., Yang, J. S., Ma, Y. S., Liao, C. L., et al. (2010). Emodin, aloe-emodin and rhein induced DNA damage and inhibited DNA repair gene expression in SCC-4 human tongue cancer cells. Anticancer Res. 30 (3), 945-951. doi: 10.1097/CAD.0b013e32833418c0

Denkert, C., Liedtke, C., Tutt, A., and von Minckwitz, G. (2017). Molecular alterations in triple-negative breast cancer-the road to new treatment strategies. Lancet 389 (10087), 2430-2442. doi: 10.1016/S0140-6736(16) 32454-0

DeSantis, C. E., Ma, J., Goding, S. A., Newman, L. A., and Jemal, A. (2017). Breast cancer statistics, 2017, racial disparity in mortality by state. CA Cancer J. Clin. 67 (6), 439-448. doi: 10.3322/caac.21412

Fernand, V. E., Losso, J. N., Truax, R. E., Villar, E. E., Bwambok, D. K., Fakayode, S. O., et al. (2011). Rhein inhibits angiogenesis and the viability of hormonedependent and -independent cancer cells under normoxic or hypoxic conditions in vitro. Chem. Biol. Interact. 192 (3), 220-232. doi: 10.1016/ j.cbi.2011.03.013

Jiang, M., Wang, T., Yan, X., Liu, Z., Yan, Y., Yang, K., et al. (2019). A Novel Rhein Derivative Modulates Bone Formation and Resorption and Ameliorates Estrogen-Dependent Bone Loss. J. Bone Mineral Res. 34 (6937), 361-374. doi: $10.1002 / j b m r .3604$

Jing, L., Huaxin, H., Danrong, L., Chunyan, M., and Chunmiao, W. (2015). Virtual screening for bioreductive inhibitors of Racl protein (in Chinese). Comput. Appl. Chem. 32 (4), 000459-000462. doi: 10.11719/com.app.chem20150415

Li, Y., Xu, Y., Lei, B., Wang, W., Ge, X., and Li, J. (2012). Rhein induces apoptosis of human gastric cancer SGC-7901 cells via an intrinsic mitochondrial pathway. Braz. J. Med. Biol. Res. 45 (11), 1052-1059. doi: 10.1590/s0100879x2012007500125

Li, Z., Su, Z., Liang, D., Wang, C., Lan, F., Li, J., et al. (2019). Construction of luciferase reporter gene cell model and its application in screening rhein derivatives targeting RAC1 (in Chinese). Chin. Pharmacol. Bull. 35 (07), 10251030. doi: 10.3969/j.issn.1001-1978.2019.07.026
Laboratory of High-Incidence-Tumor Prevention and Treatment, Guangxi Medical University, the Ministry of Education, China (Grant No. GKE2019-23).

\section{ACKNOWLEDGMENTS}

We thank the Experimental platform provided by Life Sciences Institute of Guangxi Medical University.

\section{SUPPLEMENTARY MATERIAL}

The Supplementary Material for this article can be found online at: https://www.frontiersin.org/articles/10.3389/fphar.2020. 00754/full\#supplementary-material

Lu, Y., Yao, G., and Ma, W. (2016). Rhein: a novel potential antitumor drug J. Chin. Pharm. Sci. 25 (5), 321-328. doi: 10.5246/jcps.2016.05.036

Ma, Q., Cavallin, L. E., Yan, B., Zhu, S., Duran, E. M., Wang, H., et al. (2009). Antitumorigenesis of antioxidants in a transgenic Racl model of Kaposi's sarcoma. Proc. Natl. Acad. Sci. U. S. A. 106 (21), 8683-8688. doi: 10.1073/pnas.0812688106 McAllister, S. S. (2012). Got a light? Illuminating lung cancer. Sci. Transl. Med. 4 (142), 142fs22. doi: 10.1126/scitranslmed.3004446

Nicola, F., Alberto, C., Paolo, B., Francesca, C., and Alessandro, C. (2009). Virtual screening approach for the identification of new Racl inhibitors. J. Med. Chem. 52 (14), 4087.

Pang, H., Tian, W., Kang, J., Zhao, Y., Zhai, L., Liang, D., et al. (2020). Effects of Rhein derivatives $4 \mathrm{a}$ containing amide structure on migration and invasion in ovarian cancer cells (in Chinese). Chin. Pharmacol. Bull. 36 (02), 204-209. doi: 10.3969/j.issn.1001-1978.2020.02.011

Parness,J, and Horwitz, S. B. (1981). Taxol binds to polymerized tubulin in vitro. J. Cell Biol. 91 (2 Pt 1), 479-487. doi: 10.1083/jcb.91.2.479

Patel, R. V., and Se Won, P. (2013). An evolving role of piperazine moieties in drug design and discovery. Mini Rev. Med. Chem. 13 (11), 1579-1601. doi: 10.2174/ 13895575113139990073

Payapilly, A., and Malliri, A. (2018). Compartmentalisation of RAC1 signalling. Curr. Opin. Cell Biol. 54, 50-56. doi: 10.1016/j.ceb.2018.04.009

Rathi, A. K., Syed, R., Shin, H. S., and Patel, R. V. (2016). Piperazine derivatives for therapeutic use: a patent review (2010-present). Expert Opin. Ther. Pat. 26 (7), 777-797. doi: 10.1080/13543776.2016.1189902

Ridley, A. J. (2015). Rho GTPase signalling in cell migration. Curr. Opin. Cell Biol. 36, 103-112. doi: 10.1016/j.ceb.2015.08.005

Rosenblum, M. D., and Shivers, R. R. (2000). 'Rings' of F-actin form around the nucleus in cultured human MCF7 adenocarcinoma cells upon exposure to both taxol and taxotere. Comp. Biochem. Physiol. C Toxicol. Pharmacol. 125 (1), 121-131. doi: 10.1016/S0742-8413(99)00101-2

Shi, P., Huang, Z., and Chen, G. (2008). Rhein induces apoptosis and cell cycle arrest in human hepatocellular carcinoma BEL-7402 cells. Am. J. Chin. Med. 36 (4), 805-813. doi: 10.1142/s0192415x08006259

Stallings-Mann, M. L., Waldmann, J., Zhang, Y., Miller, E., Gauthier, M. L., Visscher, D. W., et al. (2012). Matrix metalloproteinase induction of Raclb, a key effector of lung cancer progression. Sci. Transl. Med. 4 (142), 142 ra95. doi: 10.1126/scitranslmed.3004062

Su, Z., Li, Z., Wang, C., Tian, W., Lan, F., Liang, D., et al. (2019). A novel Rhein derivative: Activation of Rac1/NADPH pathway enhances sensitivity of nasopharyngeal carcinoma cells to radiotherapy. Cell Signal 54, 35-45. doi: 10.1016/j.cellsig.2018.11.015

Tang, M., Li, H., Zhou, G., Xie, Y., Ruan, H., and Li, D. (2016). Rhein inhibits the movement and invasion of human ovarian carcinoma cells through Rac1/ LIMK1/cofilin signaling pathway (in Chinese). Chin. Pharmacol. Bull. 32 (03), 366-372. doi: 10.3969/j.issn.1001-1978.2016.03.014 
Tian, W., Li, J., Su, Z., Lan, F., Li, Z., Liang, D., et al. (2019). Novel Anthraquinone Compounds Induce Cancer Cell Death through Paraptosis. ACS Med. Chem. Lett. 10 (5), 732-736. doi: 10.1021/acsmedchemlett.8b00624

Vilar, S., Cozza, G., and Moro, S. (2008). Medicinal chemistry and the molecular operating environment (MOE): application of QSAR and molecular docking to drug discovery. Curr. Top. Med. Chem. 8 (18), 1555-1572. doi: 10.2174/ 156802608786786624

Wet, J. R. D., Wood, K. V., Deluca, M., Helinski, D. R., and Subramani, S. (1987). Firefly luciferase gene: structure and expression in mammalian cells. Mol. Cell. Biol. 7, 725-737. doi: 10.1128/mcb.7.2.725

Wu, C., Cao, H., Zhou, H., Sun, L., Xue, J., Li, J., et al. (2017). Research Progress on the Antitumor Effects of Rhein: Literature Review. Anticancer Agents Med. Chem. 17 (12), 1624-1632. doi: 10.2174/1871520615666150930112631

Yajun, L., and Zhen, Y-S. (2009). Rhein lysinate suppresses the growth of breast cancer cells and potentiates the inhibitory effect of Taxol in athymic mice. AntiCancer Drugs 20, 65-72. doi: 10.1097/CAD.0b013e3283182913

Yang, C. H., and Horwitz, S. B. (2017). Taxol((R)): The First Microtubule Stabilizing Agent. Int. J. Mol. Sci. 18 (8), 1733-1743. doi: 10.3390/ ijms18081733

Yao, G. Y., Ye, M. Y., Huang, R. Z., Li, Y. J., Pan, Y. M., Xu, Q., et al. (2014). Synthesis and antitumor activities of novel rhein alpha-aminophosphonates conjugates. Bioorg. Med. Chem. Lett. 24 (2), 501-507. doi: 10.1016/ j.bmcl.2013.12.030

Yunfeng, L., Wei, T., Fu, L., Jiankang, K., Huifeng, P., Huaxin, H., et al. (2019a). A novel Rhein derivative $4 \mathrm{~F}$ anti-proliferation via paraptosis-like cell death in MCF-7 cell. J. Guangxi Med. Univ. 36 (2), 163-168. doi: 10.16190/j.cnki.45$1211 /$ r.2019.02.001
Yunfeng, L., Yanping, Z., Wei, T., Fu, L., Jiankang, K., Huifeng, P., et al. (2019b). An autophagy-dependent cell death of MDA-MB-231 cells triggered by a novel Rhein derivative 4F. Anticancer Drugs 30 (10), 1038-1047. doi: 10.1097/ CAD.0000000000000820

Zhengying, S., Wei, T., Jing, L., Chunmiao, W., Zhiyu, P., Danrong, L., et al. (2017). Biological Evaluation and Molecular Docking of Rhein as a MultiTargeted Radiotherapy Sensitization Agent of Nasopharyngeal Carcinoma. J. Mol. Struct. 1147. doi: 10.1016/j.molstruc.2017.06.123

Zhou, Y. X., Xia, W., Yue, W., Peng, C., Rahman, K., and Zhang, H. (2015). Rhein A Review of Pharmacological Activities. Evid. Based Complement Alternat. Med. 2015, 578107. doi: 10.1155/2015/578107

Zhou, G., Peng, F., Zhong, Y., Chen, Y., Tang, M., and Li, D. (2017). Rhein suppresses matrix metalloproteinase production by regulating the Rac1/ROS/ MAPK/AP-1 pathway in human ovarian carcinoma cells. Int. J. Oncol. 50 (3), 933-941. doi: 10.3892/ijo.2017.3853

Conflict of Interest: The authors declare that the research was conducted in the absence of any commercial or financial relationships that could be construed as a potential conflict of interest.

Copyright (c) 2020 Li, Liu, Zhao, Tian, Zhai, Pang, Kang, Hou, Chen and Li. This is an open-access article distributed under the terms of the Creative Commons Attribution License (CC BY). The use, distribution or reproduction in other forums is permitted, provided the original author(s) and the copyright owner(s) are credited and that the original publication in this journal is cited, in accordance with accepted academic practice. No use, distribution or reproduction is permitted which does not comply with these terms. 